\title{
TRAJETÓRIAS SOCIOESPACIAIS DOS MILITANTES DO MOVIMENTO NEGRO NA REGIÃO METROPOLITANA DE GOIÂNIA
}

\section{SOCIOSPATIAL TRAJECTORIES OF BLACK MOVEMENT ACTIVISTS IN THE METROPOLITAN REGION OF GOIÂNIA}

\section{TRAYECTORIAS SOCIOESPACIALES DE LOS MILITANTES DEL MOVIMIENTO NEGRO EN LA REGIÓN METROPOLITANA DE GOIÂNIA}

\author{
Talita Cabral Machado \\ Mestre em Geografia pela Universidade Federal de Goiás \\ Geógrafa na Diretoria de Informações Urbanas e Geoprocessamento da Secretaria Municipal de \\ Planejamento Urbano de Goiânia. \\ Rua 219 quadra 73 lote 26 Ed. José de Farias Filho, Apt. 201. Goiânia-GO. CEP: 74603-120 \\ E-mail: talita.geo@gmail.com
}

\begin{abstract}
Alex Ratts
Arquiteto e Urbanista pela Universidade Federal do Ceará.

Mestre em Geografia Humana e Doutor em Antropologia Social pela Universidade de São Paulo. Professor Adjunto do Instituto de Estudos Socioambientais da Universidade Federal de Goiás. Coordenador do Laboratório de Estudos de Gênero Étnico-Raciais e Espacialidades - LaGENTE. E-mail:ratts@iesa.ufg.br
\end{abstract}

\section{Resumo}

O objetivo é refletir a produção do espaço urbano a partir das trajetórias socioespaciais individuais e coletivas dos(as) militantes do movimento negro. Os sujeitos que participam do movimento constroem suas identidades a partir do seu corpo negro, o que remete às expressões culturais, religiosas e políticas de cunho racial. A atuação do movimento negro na região metropolitana de Goiânia se materializa no espaço urbano através das trajetórias no bairro, no trabalho, na escola, na universidade, nos locais de lazer, nos locais de militância. A complexidade e diversidade de lugares descobertos, produzidos e fortalecidos pelos(as) militantes desse movimento, remete a compreensão da cidade a partir de um recorte racial e no sentido de construção de territorialidades negras e de matriz africana na cidade. Novos/velhos territórios na cidade são descobertos, fortalecidos e produzidos pelos que participam do movimento negro.

Palavras-chave: movimento negro, trajetória socioespacial, espaço urbano, territorialidade.

\begin{abstract}
The aim is to reflect the production of urban space from the trajectories of individual and collective socio-spatial of militant black movement. The subjects who participate in the movement, construct their identities from their black body, which refers to cultural, religious, and racialized policies. The performance of the black movement in the
\end{abstract}


metropolitan region of Goiânia is materialized in the urban space through the trajectories in the neighborhood, at work, at school, at university, in places of leisure, in local activism, which spatial distribution. The complexity and diversity of discovered, produced and strengthened places by (the) militants of the movement, refers to understanding the city from a race and in a sense of the construction of black territoriality and the African matrix in the city. New/old territories are discovered, sustained and produced in the city by whom participate in the black movement.

Keywords: movement black, sociospatial trajectory, urban space, territoriality.

\section{Resumen}

El objetivo es reflejar la producción del espacio urbano a partir de las trayectorias socioespaciales individuales y colectivos de los militantes del movimiento negro. Los sujetos que participan de lo movimiento construyen su identidad a través de su cuerpo negro, que se refiere a las expresiones culturales, religiosas y políticas de la raza. El papel del movimiento negro en la región metropolitana de Goiânia materializan en el espacio urbano a través de las trayectorias en el barrio, en el trabajo, en la escuela, en la universidad, en los lugares de ocio, en los locales de militancia. La complejidad y diversidad de los lugares descubiertos, producidos y fortalecidos por los militantes del movimiento, se refieren a la comprensión de la ciudad a partir de un recuerte racial y en un sentido de construcción de las territorialidad negras e de matriz africana en la ciudad. Territorios nuevos/viejos son descubiertos, sostenidos y producidos en la ciudad por los que participacipan de el movimiento negro.

Palabras-clave: movimiento negro, trayectoria socioespacial, espacio urbano, territorialidad.

\section{Introdução}

O movimento negro é uma rede temática transnacional que liga os movimentos locais, regionais, nacionais e internacionais e se entrecruza com outras redes de movimentos sociais. No Brasil, o movimento negro agrupa as entidades de caráter político, cultural, grupos formando coletivos dentro de outros grupos, etc.

Hoje, o movimento negro é unidade analítica e política e se caracteriza por uma pluralidade de formas de organização, formas de ação e intervenção social e uma complexidade das pautas. Como por exemplo, as entidades de caráter cultural, político, grupos formando coletivos dentro de sindicatos, de universidades, de grupos formando núcleos de estudos afro-brasileiros e propondo produção do conhecimento, ONGs, grupos disputando o plano de construção das leis, professores negros e negras que encaram a luta anti-racismo dentro da trajetória escolar, etc. 
O movimento negro organizado nas cidades brasileiras reivindica a inserção da população negra nos espaços na sociedade e melhorias das condições de vida. Os grupos levantam questões que muitas vezes representam um desfio para os pesquisadores brasileiros. As relações raciais, a miscigenação, o preconceito racial e a segregação racial são alguns temas estudados no Brasil.

Surge então para os(as) Geógrafos(as), um desafio: entender como o espaço na cidade se produz a partir do movimento negro, utilizando-se da abordagem geográfica para entender o real. Para tal, é necessário compreender as expressões territoriais, as linguagens de representação dos movimentos sociais e estudar os sujeitos que grafam a terra a partir do espaço enquanto experiência (mapas mentais) e da valorização do ato de ouvir $^{1}$. Dentre outros, são os militantes dos movimentos sociais que nos mostram as agruras da vida quotidiana e os espaços dos grupos esquecidos devem ser hoje o espaço da análise dos geógrafos ${ }^{2}$.

Pretende-se, portanto, instigar um olhar de geo-grafias da região metropolitana de Goiânia a partir da trajetória socioespacial dos(as) militantes do movimento negro. Bem como explorar possibilidades de análises, descobrir e inspirar Geografias na construção das construções raciais pensadas espacialmente.

Este trabalho propõe discutir a trajetória na cidade, no bairro, a trajetória familiar/memória, no trabalho, na escola, nos locais de lazer e nos locais de militância dos(as) entrevistados(as) participantes de entidades do movimento negro na região metropolitana de Goiânia. O objetivo é refletir a produção do espaço urbano a partir das trajetórias socioespaciais individuais e coletivas dos(as) militantes do movimento negro.

O presente trabalho caracteriza-se como uma pesquisa qualitativa. Para a entrevista, foram escolhidos militantes de sete (7) entidades do movimento negro de cunho político $^{3}$ com suas sedes localizadas na região metropolitana de Goiânia. As entidades são: CACUNE (Casa de Cultura da Comunidade Negra de Goiás), CANBENAS (Coletivo de Estudantes Negros Beatriz Nascimento), APNs (Agentes de Pastorais Negros), Grupo de Mulheres Negras Dandara no Cerrado, Centro de

\footnotetext{
${ }^{1}$ Carlos Walter Porto-Gonçalves, comunicação oral, Encontro Nacional de Geógrafos, em Porto Alegre, em julho de 2010.

${ }^{2}$ Boaventura Souza Santos, comunicação oral, Encontro Nacional de Geógrafos, em Porto Alegre, em julho de 2010.

${ }^{3}$ Considerar-se que existam grupos culturais que possuem também um caráter político e de luta contra a discriminação. E em muitas entidades do movimento negro, o político e cultural de misturam.
} 
Referência Lélia Gonzalez, Associação Pérola Negra e CENEG-GO (Centro de Cidadania Negra do Estado de Goiás).

Espera-se que este trabalho possa contribuir para a sociedade e para o estudo em Geografia sobre as questões raciais. Possibilitando um melhor entendimento da dinâmica do espaço urbano. Uma tarefa desafiadora que abre a possibilidade de complexificar a interpretação e a imaginação geográfica ao incorporar elementos que, por vezes, são tratados de maneira desvinculada.

\section{Movimento Negro e o Espaço Urbano}

Santos (2008) utiliza o quadro referencial apresentado por Gohn (1991), para listar as diversas maneiras de analisar os movimentos sociais urbanos e cada uma delas confere diferentes significados às ações de seus participantes. Umas dessas formas de analisar o movimento social compreende o "enfoque neoidealista" (SANTOS, 2008, p.23). Seus principais representantes são Foucault, Deleuze e Guatari, entre outros autores influenciados pelo pensamento anarquista e marxista ${ }^{4}$ (SANTOS, 2008).

O enfoque neoidealista confere importância aos chamados movimentos de minorias, ou como para Ratts (2009), movimentos vinculados com a questão da diferença étnica, racial, etária ou de gênero, que correspondem aos movimentos de mulheres, de negros, de homossexuais e ambientalistas, "criadores de uma nova sociedade, potencializada por mudanças socioculturais (mudanças de hábitos e de atitudes mediante a militância)" (SANTOS, 2008, p. 24). Para Santos estes movimentos sociais:

Seriam construtores de espaços novos - territórios de singularidades - nos quais os indivíduos poderiam expressar seus desejos que foram frustrados ou reprimidos pela força do Estado. Indivíduos desterritorializados reterritorializam a cidade em suas formas específicas de apropriação desta. (SANTOS, 2008, p. 24, grifos da autora)

Porém para os autores desta corrente, a não-institucionalização do movimento é fundamental para a conquista da sua autonomia. Porém, o movimento negro é uma rede de movimento social que abarca outras redes temáticas, por possui esta complexidade na sua organização e ação, alguns das suas entidades buscam maior representatividade política no intuito de gerar mudanças de valores sociais e pela justiça social. A ação do

\footnotetext{
4 Influenciados por pensadores como Proudhon e Kropotkin (anarquistas) e Agnes Heller,
} Habermas e Marcuse (marxistas). 
movimento negro no meio urbano estaria vinculada com a ampliação dos direitos de cidadania.

Os Movimentos sociais urbanos realizam, entre outras ações, diferentes atividades educativas na cidade. Proporcionando a promoção da participação social, a viabilização e incentivo da vida coletiva. Eles são também responsáveis pela formação de uma cidadania crítica, participativa e aberta para a diversidade no espaço urbano. $\mathrm{O}$ movimento negro forma cidadãos para participarem também da gestão urbana.

O espaço urbano propicia a construção da vida coletiva, mas a ordem que orienta a produção desse espaço segue as leis da produção capitalista, em que a individualidade e o agravamento da desigualdade social ocorrem. Os movimentos sociais organizados na cidade e outros agentes possibilitam a comunicação para a efetivação do espaço urbano como local de encontro e de respeito à diversidade.

Segundo Cavalcanti (2007), para compreender o aparente caos da metrópole é necessário analisar amplamente como é o movimento das e nas cidades e a lógica que os orienta. Essa tarefa é complexa e exige esforços transdisciplinares. Existe um ordenamento que orienta a produção do espaço urbano, "mas para ir além dele, ou para captá-lo realmente, é preciso ver a vida que o anima” (CAVALCANTI, 2007, p. 12). Portanto é preciso compreender a cidade também como a materialização de modos de vida e como espaço simbólico.

É dando ouvido aos militantes, a partir das falas sobre suas trajetórias socioespacias na cidade e no bairro, a trajetória familiar/memória, no trabalho, na escola, nos locais de lazer e nos locais de militância dos sujeitos que compõem o movimento, que este trabalho se orienta. Percebe-se como o espaço da cidade é produzido por esses agentes, como as suas ações políticas e política-culturais se materializam nele.

\section{Militância e Trajetória Socioespacial: "espaços" ocupados na cidade}

A memória dos trajetos dos(as) militantes indica espaços de conflitos na cidade. Todos os entrevistados(as) narraram fatos, ligados à questão da inferiorização do corpo negro, vivenciados durante a infância, juventude e na fase adulta. Antes de participarem do movimento negro, as reações diante de tais fatos eram de conflito ou silêncio. 
O corpo possui marcas que ideologicamente interpretadas indicam o lugar e a posição social do indivíduo nos espaços. Mesmo nos espaços públicos, onde todos deveriam ter o mesmo direito, como para Gomes:

Fisicamente, o espaço público é, antes de mais nada o lugar, praça, rua, shopping, praia, qualquer tipo de espaço, onde não haja obstáculos à possibilidade de acesso e participação de qualquer tipo de pessoa. Essa condição deve ser uma norma respeitada e revivida, a despeito de todas as diferenças e discórdias entre os inúmeros segmentos sociais que ai circulam e convivem, ou seja, as regras do convívio e do debate devem ser absolutamente respeitadas". (GOMES, 2002, p. 162)

Porém, existem outros fatores que acabam regulando a vivencia no espaço público, como o próprio Gomes coloca: "sobre este espaço se constitui e se desenvolve assim um certo código de conduta, código este que é estabelecido pelo relacionamento, na co-presença e na coabitação" (2002, p. 163).

Podemos inferir a partir dessa leitura que o espaço público possui além das determinações das normas e regras do estatuto, também "códigos invisíveis mais profundos que impõem dinâmicas próprias a cada espaço" (RODRIGUES \& RATTS, 2007, p. 8). Assim, cada grupo social (negros, brancos, mulheres, homens, homossexuais, heterossexuais, ricos, pobres, etc.) viverá de forma diferenciada o espaço público (pois estes grupos possuem, quase sempre, marcas corporais hierarquizadas na sociedade).

As representações sociais e simbólicas estigmatizadas e preconceituosas existentes no imaginário dos atores sociais colocam o corpo negro como inferior em certos espaços. Existe, portanto, uma incompletude da cidadania para alguns atores.

Há um relativo cerceamento da inserção dos corpos negros nos espaços públicos e privados enquanto cidadãos ou restringindo-os às posições inferiores, fruto da combinação entre condição social e racismo. Segundo Ramos "é o corpo que estrutura as narrativas do espaço, selecionando, saltando, agrupando, criando limites, barreiras e fronteiras". (RAMOS, 2002, p. 296).

Podemos a partir da compreensão de Raffestin, em que "o poder se manifesta por ocasião da relação" (RAFFESTIN, 1993 p. 53), e estas se dão entre indivíduos diferentes, dizer que o corpo é um instrumento de poder. Pois ele é a maior escala material das relações. Numa sociedade racista, onde o corpo negro é inferiorizado, 
muitas vezes, a experiência em certos espaços para o homem e a mulher negra é sofrida e reflete na construção da sua subjetividade e nos seus trajetos.

Costa (1984) examina a violência do racismo a partir da estigmatização do corpo negro, que é investido de um sentido negativo. Para ele uma das características da violência racista é:

Estabelecer, por meio do preconceito de cor, uma relação persecutória entre o sujeito negro e seu corpo. O corpo ou imagem corporal eroticamente investida é um dos componentes fundamentais na construção da identidade do indivíduo. A identidade do sujeito depende, em grande medida, da relação que ele cria com o corpo. A imagem ou enunciado identificatório que o sujeito tem de si estão baseados na experiência de dor, prazer que o corpo obriga-lhe a sentir a pensar. (COSTA, 1984, p. 107)

O espaço escolar é colocado pelos(as) entrevistados(as) como local onde ocorrem as tensões e conflitos ligados à questão racial. A escola possui um papel importante para a conscientização sobre a questão racial, mas é ao mesmo tempo local de reproduções discriminatórias da sociedade.

Todos(as) os(as) entrevistados(as) viveram algum tipo de constrangimento na escola relacionado à questão racial e algumas dessas experiências marcaram negativamente suas trajetórias. Uma das consequiências mais violentas do racismo é quando o aluno internaliza a ideia de inferioridade e incapacidade, interferindo no seu rendimento escolar e posteriormente na sua realização profissional.

As conseqüências do racismo são vistas como prejudiciais e com repercussão negativa na motivação ao estudo e no baixo rendimento escolar. Como para Silva (2006) que conclui a partir da pesquisa sobre segregação espacial e racial em São Paulo:

O maior problema não está no acesso da criança a escola, mas sobretudo na sua permanência na instituição escolar, visto que é nela que se confrontará mais fortemente o racismo. A escola continua sendo um dos lugares traumáticos para as relações raciais. (SILVA, 2006, p.159)

Os espaços profissionais também foram mencionados como local de conflitos. Podem-se fazer duas distinções de espaços profissionais onde os(as) militantes negros trabalhavam ou trabalham. O primeiro está ligado a lugares que como para Lélia Gonzalez (1982) são compreendidos como "lugar de negro" na sociedade, isto é, "o espaço social e as áreas de trabalho (...) inferiorizadas destinadas à população negra desde o longo período escravista" (RATTS \& RIOS, 2010, p. 145) até o pós-abolição. Esses trabalhos estão presentes na história de quase todos os(as) militantes 
(principalmente os mais velhos) e estão ligados aos trabalhos subalternos, como: doméstico, babá, engraxate, vendedor em redes de supermercados, trabalhos manuais em empresas, etc. E o outro espaço profissional corresponde aos trabalhos ligados à ascensão educacional dos(as) militantes, que são o de professor, economista, pesquisador, etc. Ambos os espaços profissionais compreendem a locais de conflitos ligados à questão racial na relação com os atores, mas esses conflitos possuem lógicas um pouco diferentes.

Todos(as) os(as) entrevistados(as) narram diversas situações que podem ser interpretadas como racistas vividas nos espaços profissionais. A entrevistada conta que trabalhou como empregada doméstica numa casa e que não teve o direito de sair do trabalho. A relação entre a patroa e a empregada doméstica é hierárquica e possui remanescentes do período colonial projetado no tempo através do corpo:

Eu tentei sair de lá e a mulher não quis devolver minhas roupas, $e$ dizia que enquanto eu não terminasse o mês e ela não arranjasse outra pessoa eu não iria sair dalí. E eu dizia que iria sair sim e agora. E aí ela descuidou e eu pulei o muro e fui embora. (Entrevistada I, 42 anos. Data da entrevista: fevereiro de 2011)

O corpo negro, muitas vezes, é rejeitado nos espaços profissionais ligados à ascensão educacional dos(as) militantes. Existe uma posição social predeterminada, ligada aos trabalhos subalternos, para o corpo negro nesses espaços profissionais. Como explicita o militante A:

Eu estava na Assembléia Legislativa num evento, aí uma senhora chegou e me falou assim: Moço o garrafão de água mineral acabou. Não estava entendendo o que ela estava querendo dizer, e ela dizia "Acabou. Tem como trocar?" E eu "ah! sim! Tem como trocar, mas precisa procurar um funcionário daqui da casa pra poder trocar, porque eu não trabalho aqui, mas vamos descobrir alguém que faz isso". Por quê? Já existe um estereotipo formado na cabeça das pessoas do qual, às vezes um negro de terno e gravata, ele tem que ser garçom, ele tem que ser segurança, ele tem que está em funções subalternas. (...) As pessoas às vezes não conseguem perceber que você pode ser um gestor, um advogado, um assistente social. (Entrevistado B, 42 anos. Data da entrevista: julho de 2010)

Verifica-se também uma rejeição do corpo negro em trabalhos onde a "aparência" é fundamental, numa sociedade onde o padrão de beleza é branco. Existe uma dificuldade encontrada na aceitação do corpo negro nestes locais. A entrevistada 
relata uma de suas experiências vivenciada no shopping de um bairro de classe alta em Goiânia:

O gerente fez uma entrevista comigo, tinha olhado meu currículo e tinha gostado e nisso eu não usava mais o cabelo escovado, mas natural. Ele tinha me dado certeza que eu iria ficar com aquele cargo numa loja de sapatos (...). Ele deu a entender que eu iria ficar com o cargo e no final da entrevista ele pediu que eu desse um jeito no meu cabelo, uma melhorada. Eu entendi que o meu cabelo não é bom para estar alí, atendendo o publico naquele shopping. (Entrevistada F, 28 anos. Data da entrevista: janeiro de 2011)

Para Gomes, "é no corpo que se dão as sensações, as pressões, os julgamentos. Esses não acontecem de forma independente, mas estão intimamente entrelaçados, constituindo uma estrutura, uma unidade que tem uma ordem - a sua forma de corpo" (2006, p. 261). Segundo a autora, o cabelo é um dos elementos mais visíveis e destacados do corpo. E a maneira como o indivíduo pensa o cabelo e expressa seu sentimento em relação a ele, pode significar muito como essas pessoas se reconhecem como negra ou não. A autora afirma que o entendimento da simbologia e a forma de manipulação de diferentes partes do corpo negro (entre elas o cabelo) pode ser um caminho para compreender a identidade negra na sociedade brasileira (GOMES, 2006). A inferiorização ou a vulgarização do corpo negro pode significar uma barreira para o reconhecimento racial.

Nos trajetos quotidianos dos(as) entrevistados(as), percebem-se espaços na cidade que rejeitam seus corpos e são locais de discriminação racial mais ou menos explícito e outros onde eles parecem pertencer, os "lugares negros" (RATTS, 2011). Portanto, a raça/cor influencia a experiência e a compreensão que o indivíduo possui do espaço. Como indica Massey "não é só a economia que determina nossa experiência de espaço e lugar (...) há muito mais coisas determinando nossa vivencia do espaço do que o 'capital"' (MASSEY, 2000, p.179, grifos da autora). Os trajetos, deslocamentos e caminhos dos indivíduos são influenciados pelo seu dado corpóreo e os conflitos surgidos nesse processo marcam suas vidas, muitas vezes, determinando os locais onde eles estarão ou não.

Já no espaço privado, a casa, a questão racial, para a maioria dos(as) entrevistados(as), não era discutida, ao contrário, muitas vezes, era negligenciada pela família. Durante a infância de muitos(as) entrevistados(as), a negritude foi negada e havia a preocupação da família em afirmar uma "morenidade". Muitos desses(as) 
militantes narraram fatos racistas vivenciados dentro da família, sempre inferiorizando os marcos negros do corpo. Todas essas famílias eram compostas, nos mais diversos graus de parentescos, por pessoas negras e brancas.

Apenas na família da entrevistada L, em que todos eram negros, a negritude não era negada, ao contrário, era lembrada o tempo todo, muitas vezes como um obstáculo maior para a ascensão social, a ser superado e não negado. Como na sua fala:

Isso nunca foi nos negado. E meu pai e minha mãe era um casal de negro, não sei se sorte ou azar, meu tio e minha tia eram um casal de negro, meus avôs e minhas avós, todas, porque avô teve cinco esposas e todas eram negras. Nós tínhamos um círculo familiar de pessoas que tinham um comportamento de negros, sem aquela necessidade de esconder isso. Das tranças de cabelo que minha mãe fazia, nos assuntos que nós conversávamos, no modo de vida que minha vó tinha e que minha mãe herdou (...). Então nós tínhamos a compreensão de quem nós éramos, não tínhamos dificuldade em entender isso. Mas tinha o sofrimento da não aceitação dos outros, tinha o conflito lá fora. (Entrevistada L, 45 anos. Data da entrevista: fevereiro de 2011)

Muitas mulheres entrevistadas já tinham sua trajetória traçada no imaginário dos seus familiares: trabalhar cedo como empregada doméstica, casar, ser mãe e dona de casa. Como conta a entrevistada:

E aos quatorze eu já fui trabalhar mesmo, que é a trajetória das minhas irmãs, elas começavam aos doze, treze anos iam para as casas das senhoras e moravam lá e só saiam depois, voltavam para casa aos domingos, porque elas trabalhavam aos sábados e depois saiam para casar. Quando eu, com quatorze anos, fui para essa mesma trajetória das minhas irmãs e vivenciei aquela coisa que é tipo escravidão mesmo. Porque você levanta cinco e meia da manhã, para arrumar o café e você dorme lá no quartinho sozinha. (Entrevistada I, 42 anos. Data da entrevista: fevereiro de 2011)

O espaço privado para a mulher negra é marcada pela inferioridade gerada tanto pela cor da pele como pelo gênero. A sobrecarga dessas mulheres é grande e à elas são reservado os lugares da casa como: a cozinha, o fogão, o tanque. Muitos entrevistados(as) foram criados apenas pela mãe, que sustentou a casa como lavadeira e empregada doméstica, e que sofreu o estigma de sua inferioridade causado pela cor.

Para todos(as) os(as) entrevistados(as), a questão racial foi profundamente pensada e discutida somente depois da entrada no movimento negro. Ocorreu uma profunda mudança nas formas de agir e ocupar os espaços da cidade. Onde ocorria o silêncio ou conflito, agora se propõe o diálogo com argumentação. 
O trabalho dos(as) militantes no movimento negro parte da valorização do corpo e da cultura negra. Um trabalho de desconstrução de hierarquias e construção de novas subjetividades. Os(as) militantes utilizam a corporeidade como instrumento inverso da relação de poder, a partir da valorização e orgulho de seu corpo.

Muitos espaços da cidade são ocupados diariamente por aqueles que militam no movimento negro. Não só no sentido de estar presente, mas ocupar no sentido de construir novas interpretações simbólicas dos atores no espaço. A militante L conta como ocorre a sua ocupação nos espaços:

Eu fui forçando muito a minha entrada em vários espaços. (...) Eu tinha problemas com os pais dos alunos, que eles sonhavam para os filhos deles que estavam entrando na alfabetização, um outro tipo de professora. (...) o que tinha que ser avaliada era a minha competência, mas eles tinham que me enxergar enquanto negra. Arrombar as portas dessas famílias, para que elas pudessem reconhecer que uma mulher, jovem, negra tinha a capacidade de alfabetizar seus filhos. (...) Agora tem espaços que nos rejeitam, mas eles não oficializam isso. (...) Eu estive em espaços que me expulsavam e eu tive que resistir. (Entrevistada L, 45 anos. Data da entrevista: fevereiro de 2011)

Depois de participar do movimento, a militante $F$ narra que o seu constrangimento em certos locais é trabalhado diariamente e a sua presença e postura nos espaços se transformaram:

Eu não vou a alguns lugares porque eu não tenho tempo e dinheiro. E em outros me sinto meio constrangida, por conta da postura das pessoas com relação a minha presença. Porque às vezes as pessoas te olham e te mapeiam, olham o cabelo, fazem toda uma leitura. Dependendo de algumas lojas, é mais recorrente, dependendo do estabelecimento, tipo um bar e restaurante, isso acontece. Existe uma diferenciação. Mas eu acho que tenho que ir mesmo nesses lugares para ocupar esses espaços, não posso ficar constrangida. .(Entrevistada F, 28 anos. Data da entrevista: janeiro de 2011)

Mas a ocupação dos(as) militantes vai além, se materializando no plano político. Políticas públicas são criadas no intuído de estabelecer a presença do corpo negro em certos espaços da sociedade. Portanto a luta social, a luta do movimento negro é uma luta pelo espaço, pois como para Porto-Gonçalves:

[...] a dialética entre o ser $e$ o dever ser se instaura não como categoria abstrata, mas no chão concreto das lutas, nas lutas. Afinal, toda(o) aquela(e) que se sente oprimido ou explorado diz querer mais espaço (...) as mulheres querem mais espaço, os negros querem mais espaço, os sem-terra ocupam, isto é se co-locam (...) Enfim, os 
diferentes grupos sociais re-significam o espaço e assim, com novos signos grafam a terra, geografam, reinventando a sociedade. A Geografia, deste modo, de substantivo se transforma em verbo - ato de marcar a terra. (PORTO-GONÇALVES, 2006, p.21).

Quando o(a) militante ocupa, das maneiras mencionadas, os "espaços" da cidade, ele(a) participa da construção de novas espacialidades. O próximo item discuti a materialização no espaço urbano das ações do movimento negro a partir dos sujeitos que reinventam a metrópole goianiense.

\section{Militância e Trajetória Socioespacial: construção e fortalecimento de territorialidade negras na cidade}

Os(as) militantes se reúnem para refletir as questões raciais e discutir propostas de ações na cidade. Eles elaboram projetos principalmente ligados à corporeidade, no intuito de trabalhar a auto-estima das mulheres e homens negros(as). A entrevistada A refere-se à importância do primeiro passo do trabalho da entidade com os(as) militantes, que constitui o trabalho com a auto-estima e conscientização sobre a questão racial:

Nós da Organização X, trabalhamos a questão da formação, com a juventude, com as mulheres, da reflexão, da mulher negra, da sociedade, da questão cultural. Eu acho que o grande desafio do movimento em si e das organizações é essa, é trabalhar a comunidade, fazer a mulher negra se conscientizar do papel dela enquanto o que é de direito dela, o que ela sofre. Eu vim identificar e entender o racismo que eu sofri na minha infância só hoje, depois de participar do movimento. (Entrevistada A, 39 anos. Data da entrevista: julho de 2010)

A discussão se estende a muitas redes temáticas como da educação, da cultura e do trabalho, como na fala do militante:

No ano 2000 também eu passei a incorporar na área empresarial a Organização $Y$, do qual trouxemos pra cá uma discussão sobre a importância da inclusão pelos negócios. Uma visão diferente.(...) Esse segmento empresarial ele traz outra visão de que o racismo de fato ele está na sociedade, numa economia que é capitalista, numa economia que é fundada, que a sua fundação tem ciclos básicos e está na relação do comércio. (Entrevistado B, 42 anos. Data da entrevista: julho de 2010)

Mas a ação dos(as) militantes vai além, se projetando também no seu dia a dia e nas suas trajetórias espaciais na cidade. A questão racial é pensada e discutida o tempo 
todo na vida dos(as) militantes, no trabalho, na escola, na universidade, no lazer, nos encontros religiosos, nos trajetos.

Para muitos entrevistados(as), a entrada no movimento negro representou uma nova percepção da cidade, muitos começaram a freqüentar lugares religiosos, culturais, políticos até então não descobertos por eles. Percebe-se uma mudança no deslocamento dentro da cidade. $\mathrm{O}$ entrevistado $\mathrm{J}$ diz que a sua participação na entidade do movimento negro foi essencial para o acesso a certos "espaços" na cidade:

E a Organização $Z$ me deu acesso, dentro desse contexto da universidade, também a locais diferentes do que eu ia antigamente. De determinadas festas, que o próprio pessoal da Organização $Z$ e do movimento negro organizava, de atividades políticas, não só nas universidades e nas sedes das entidades, mas também nas sedes do governo. Nós pudemos acessar a esses lugares que eu nunca imaginava, pense numa pessoa da periferia, acha que nem pode entrar, imagina! Você passa pelo Palácio das Esmeraldas e acha que nem pode entrar ali. (Entrevistado J, 29 anos. Data da entrevista: fevereiro de 2011)

Há a redescoberta das religiões de matrizes africanas, de locais de lazer onde ocorrem as expressões artísticas e/ou religiosas de cunho racial, como a capoeira, o hiphop, as congadas, o samba de roda, o pagode, o candomblé e a umbanda. Algumas entidades políticas do movimento negro incorporam nas suas ações, oficinas culturais de caráter "afro" para envolver as crianças, os adolescentes e os jovens na discussão da questão racial e para a valorização da negritude. A militante $\mathrm{G}$ narra a mudança ocorrida na auto-estima de seu sobrinho depois de colocá-lo para participar das atividades culturais de cunho racial:

Minha irmã pagava colégio particular pro meu sobrinho achando que ele não seria descriminado e assim mesmo os meninos da escola puseram o apelido dele de Buiu e ele não aceitava de jeito nenhum e chegava todo dia chorando em casa e não queria estudar.(...) Eu pedi pra minha irmã botar eles na capoeira. E sempre levava eles, punha a calça branca neles e levava pros eventos do movimento e lá jogavam capoeira, brincavam, iam às celebrações pra jogar capoeira. Aí acabou o problema da negritude dele, assumiu ser negão. Hoje anda de cabelo trançado, vive em roda de pagode (...). Então todos vieram junto comigo, não só eles, mas todas as pessoas de onde eu trabalhei. (Entrevistada G, 55 anos. Data da entrevista: fevereiro de 2011)

A entrevistada $\mathrm{F}$ conta que ao entrar no movimento negro, além da nova percepção sobre a questão racial, o convívio com outros(as) militantes a levou a freqüentar novos lugares na cidade: 
Eu comecei a ir num terreiro de candomblé, que fica na região sul de Goiânia, no setor Pedro. E depois de um tempo, eu também comecei a frequentar a capoeira. Isso tudo por conta da vivencia com as pessoas que estavam militando no movimento negro. (Entrevistada F, 28 anos. Data da entrevista: janeiro de 2011)

A entrevistada $\mathrm{C}$ conta que a participação no movimento representou uma nova relação de lazer na cidade. Mas também houve uma mudança da sua percepção sobre as religiões africanas:

Os lugares mais diferentes e aos meninos que são africanos eu não tinha acesso. Que eu tive acesso através do Movimento. (...) E na verdade depois que eu passei a ter conhecimento, é assim, a pessoa é umbandista ou candomblecista e aí ela morre de medo de falar. E eu descobri que tem muitos, mais muitos dos meus amigos que são de religiões de matriz africana. Nisso eu passei a ter um contato maior, mais visitas aos espaços religiosos, agora eu vou estudar umbanda e candomblé. (Entrevistada C, 23 anos. Data da entrevista: julho de 2010)

O movimento negro e suas representações governamentais estão entre os responsáveis por políticas de declaração da religião e cor nos censos de 2010, como uma forma de os praticantes de religiões de matrizes africanas enfrentarem esse processo secular de estigmatização de suas práticas religiosas, de forçar a sociedade em geral a refletir sobre a importância do respeito às diferentes práticas religiosas e permite ainda que o Censo 2010 possa trazer uma visibilidade passível de utilização em políticas públicas.

Outros(as) militantes, depois de participar do movimento negro, percebem sua religião afro-brasileira e suas expressões culturais valorizadas. $\mathrm{O}$ militante $\mathrm{H}$ diz que na Cidade de Goiás onde passou a infância, participava de congos e Folias de Reis. Já em Goiânia conheceu novos elementos da cultura afro-brasileira e considera que foi reeducado depois de participar de grupos que discutiam a questão racial:

(...) Já em Goiânia, eu conheci outros elementos da cultura afrobrasileira, primeiro a capoeira. (...) Em seguida eu conheci o funk soul. Não é o funk tigrão, é o funk soul do Tim Maia. Era dançarino de funk e depois eu conheci o hip-hop. Começamos a dançar o break dance e depois começamos a cantar e hoje nós temos três cds gravados. Na minha adolescência aqui em Goiânia eu ia muito aos bailes Black. Tinha muito contato com a cultura negra, da capoeira, do hip-hop, rap, break, grafite, dj, essa foi a minha reeducação.(Entrevistado H, 38 anos. Data da entrevista: fevereiro 2011) 
Percebe-se uma rede de encontros, nos momentos de lazer, entre os(as) militantes na região metropolitana de Goiânia. Ela é constituída pelas entidades do movimento negro e é responsável por produzir uma nova forma de circular, perceber a cidade pelos sujeitos.

Nas atividades que as ONGs promovem, educativas, sociais de confraternização. É uma rede que existe em Goiânia e em Goiás. Sempre há alguém fazendo alguma coisa, difícil um final de semana que não tenha. E você começa a frequentar e vira uma troca de experiências mútuas. E forma uma rede de amizade muito sadia. Acho que o movimento negro tem ganhado muito com isso. Pois consegue reuni, dialogar, planejar ações coletivas juntas. (Entrevistado $\mathrm{H}, 38$ anos. Data da entrevista: fevereiro de 2011).

Muitos(as) militantes entrevistados(as) em seus dias de lazer visitam as comunidades quilombolas do Estado de Goiás e participam também das Festas de Congadas. A entrevistada narra os locais de lazer que extrapolam a região metropolitana e se estende às comunidades quilombolas de Goiás

Gosto de ir pra chácaras, pros quilombos, de Minaçu, a Comunidade da Dita, no quilombo Kalunga. Nas festinhas do movimento eu também vou. A gente faz festinha, pagode. Vou nas festas da Congada. (Entrevistada G, 55 anos. Data da entrevista: fevereiro de 2011).

Esta rede de relacionamentos entre os congadeiros, os quilombolas e os(as) militantes do movimento negro político urbano gera uma troca de experiência e contribui para reunir as atuações entre as diferentes entidades e redes temáticas do movimento. Como mostram a apresentação e participação dos congadeiros no encontro regional dos APNs e os casamentos "afro" em comunidades católicas em Goiânia.

Nota-se nas falas dos(as) militantes que a entrada nas religiões de matriz africana proporcionada principalmente pela participação no movimento negro, é considerada como um marco e uma passagem na construção de suas subjetividades e identidades. Como se percebe nas duas falas abaixo:

E a Organização $Z$ me deu acesso (...) também no campo religioso. (...) lá perto de casa sempre tinha oferenda. Mas aquilo para minha mãe era horrível. Quando era criança fazia até algumas sacanagens, a gente passava e jogava pedra, falava que era coisa do demônio, falava aquilo que as pessoas falavam, porque criança abarca as coisas dos adultos. E eu comecei a frequentar esses lugares, acho que foi muito importante ter conhecido o candomblé também. Para me conhecer um pouco mais. Eu fui em Salvador, e a casa que eu tive 
acesso teve uma influencia grande em mim. (Entrevistado J, 29 anos. Data da entrevista: fevereiro de 2011)

Na fala do militante B a construção da identidade é mencionada a partir da descoberta, do conhecimento de espaços religiosos na cidade:

No toque do tambor (imitando toque de tambor com as mãos) você começa a criar identidade. Criar uma identidade cultural. Porque até então você não tem essa percepção de mundo, porque você está aculturado, porque você dentro da sociedade, que ela é patriarcal, que tem uma orientação religiosa especifica pela colonização do Brasil, mas a partir do momento que ela vai se conhecendo, que ela vai se entendendo, então vai tendo descobertas e essas descobertas provavelmente vai promover um deslocamento. Do seu mundo, do seu Universo. (Entrevistado B, 42 anos. Data da entrevista: julho de 2010)

Já a militante $\mathrm{C}$, diz construir uma identidade negra a partir das leituras e aprofundamento sobre as relações raciais proporcionadas pelos encontros e conversas com outros(as) militantes do movimento negro:

$\grave{A} s$ vezes você age em algumas questões, mas falta aquela fundamentação. Você sabe que está sendo discriminado, mas falta fundamentação. E o movimento dava esse respaldo teórico (...) e assim você assumi com mais profundidade a sua identidade. (...) E o movimento ajudou a eu libuir dessa identidade afrodescendente, $e$ falar "sou negra". Porque é muito comum as pessoas não terem identidade, e falarem "eu sou filho de branco com negro, com índio, meu pai é português" então, acaba perdendo a identidade. Agora no movimento a gente vai tendo essa possibilidade de estar incorporando mesmo e dizer que eu sou afrodescendente, eu sou negra. E isso fortalece mesmo a identidade. (...) $E$ isso acaba sendo positivo. (Entrevistada C, 23 anos. Data da Entrevista: julho de 2010)

A participação no movimento negro significa uma reconstrução, baseada na questão racial, da identidade de muitos(as) militantes. Lembrando que para autores com Saquet (2010) "a identidade significa unidade na diversidade e organização política, na tentativa de transformação do lugar e de conquista de melhores condições de vida". Esse autor considera a identidade como unidade processual, relacional e mediação no desenvolvimento no e do território.

A identidade corresponde a um campo simbólico, à vida em sociedade e envolve reciprocidade. A identidade é constantemente reconstruída coletivamente e historicamente e se territorializa principalmente através das ações políticas e culturais 
(SAQUET, 2010). A identidade entendida como processo e reciprocidade/unidade entre identidade coletiva e territorialidade, são fundamentais na construção do território.

Os(as) militantes que constroem o movimento negro são produtores de territorialidades negras e de religiões e culturas de matriz africana na cidade. Novos territórios são descobertos e produzidos pelos que participam do movimento negro. Como para Mesquita “O território é (...) o mais próximo de nós. É o espaço que tem significação individual e social. Por isso ele se estende até onde vai a territorialidade. Esta é entendida como projeção de nossa identidade sobre o território." (MESQUITA, 1995, p. 83). As novas territorialidades surgem a partir do empoderamento dos(as) militantes.

Para Mesquita:

Criamos territórios ("simbólicos", "codificados") de sociabilidade que podem ser fluidos, periódicos, rítmicos nos vários espaços concretos em que transitamos, mas onde nossas raízes, em graus diversos de abertura ou de elo às antenas, continuam tentando expressar-se, para que nos demos conta do que há de transformar. (MESQUITA, 1995, p. 86)

Esses espaços transitados, ou seja, percebidos e produzidos a partir das trajetórias dos sujeitos correspondem não somente os espaços do trabalho, mas também o do lazer, o da residência, o dos afetos (mesmo se temporários). A autora aborda diz também que a consciência territorial "abre um leque de possibilidades de transformações em nós e na sociedade por interrupções nos padrões vigentes, se e quando houver tomada de consciência" (MESQUITA, 1995, p. 85).

Dematteis e Governa abrangem uma compreensão múltipla de território dizendo que "os sistemas locais territoriais são formados por redes locais de sujeitos, por um local (milieu) territorial e por um conjunto de relações, internas e externas, sendo que o sistema local opera como ator coletivo, nas interações entre redes e o ambiente, natural e cultural, local" (DEMATTEIS e GOVERNA, 2003, apud SAQUET, 2010, p. 152), o território se torna, portanto, uma rede de conexões entre o local e o global (RULLANI, 1997 apud SAQUET, 2010).

A identidade construída coletivamente através da rede de movimento negro pelos sujeitos locais que interagem entre si e com o espaço urbano pode significar uma unidade na diversidade e organização política na tentativa de potencializar as ações para a transformação do lugar e da conquista de melhores condições de vida. A ideia de negro é global. A construção da identidade e a afirmação da diferença é um fato global. 
Para Dematteis (1994 apud SAQUET, 2010), existe uma relação complementar entre o local e o global, sem eliminar o território. As condições de cada lugar (valores específicos) são transformadas em valores universais através de organizações territoriais cristalizadas em rede. O autor trabalha com o que ele denomina de "sistema local territorial” (Slot) (DEMATTEIS, 1994 apud SAQUET, 2010, p.112), que corresponde a um conjunto dotado de identidade e os sujeitos que o compõe são capazes de produzir comportamentos coletivos. O local é considerado um nó articulado em redes. Esse autor preocupa-se em produzir um conhecimento que tenha utilidade direta com a sociedade. Ele faz parte de uma vertente onde os processos de desenvolvimento local e o território são analisados através de uma perspectiva que concilia as relações território-rede-lugar (SAQUET, 2010).

Saquet escreve o conceito de territorialidade definido por Dematteis:

\begin{abstract}
A territorialidade é um fenômeno social, que envolve indivíduos que fazem parte de grupos interagidos entre si, mediados pelo território; mediações que mudam no tempo e no espaço, ao mesmo tempo, a terrritorialidade não depende somente do sistema territorial local, mas também de relações intersubjetivas; existem redes locais de sujeitos que interligam o local com outros lugares do mundo (...). O agir social é local, territorial e significa territorialidade. (SAQUET, 2010, p.115, grifos do autor)
\end{abstract}

Segundo Dematteis a política e os planos de desenvolvimento devem partir de uma geografia que reconheça as relações, geografia da territorialidade, onde as redes de sujeitos (individuais e coletivos) constituem instrumento conceitual e operativo para governar a territorialidade (SAQUET, 2010).

Partindo da concepção de Dematteis, entende-se que para subsidiar as propostas de ações políticas para um desenvolvimento que produza justiça social é preciso elaborar uma abordagem do território e da territorialidade que reconheça como uno a materialidade e a idéia, "a identidade, as relações de poder, as redes sociais e a natureza exterior ao homem" (SAQUET, 2010, p. 155). Essas ações e propostas devem "significar iniciativas de construção de identidades e territorialidades com a participação de diferentes sujeitos" (SAQUET, 2010, p. 155). O movimento negro é construtor de sujeitos coletivos, que produzem identidades e territorialidades na cidade, cujo papel é essencial para a formação mais justa do espaço urbano.

\title{
Considerações finais
}


Os sujeitos que participam do movimento constroem suas identidades a partir do seu corpo negro, o que remete a expressões culturais, religiosas e políticas de cunho racial. E a atuação do movimento negro na região metropolitana de Goiânia se materializa no espaço urbano através das trajetórias no bairro, no trabalho, na escola, na universidade, nos locais de lazer, nos locais de militância dos(as) militantes, que se territorializam.

Essa complexidade e diversidade de lugares criados pelos(as) militantes desse movimento, remete a compreensão da cidade a partir de um recorte racial e no sentido de construção de territorialidades negras e de matriz africana na cidade. Novos/velhos territórios na cidade são descobertos, fortalecidos e produzidos pelos que participam do movimento negro.

\section{Referências Bibliográficas}

CAVALCANTI, Lana de S. Cidade e vida urbana: a dinâmica do/no espaço intraurbano e a formação para a participação em sua gestão. In PAULA, F.M. de A.; CAVALCANTI, L de S. (Orgs). A cidade e seus lugares. Goiânia: Vieira, 2007, p. 1028.

COSTA, Jurandir Freire da. Violência e Psicanálise. Rio de Janeiro: Graal, 1984.

GOMES, Nilma Lino. Sem perder a raiz: corpo e cabelo como símbolos da identidade negra. Belo Horizonte: Autêntica, 2006.

GOMES, Paulo César da Costa. A condição urbana: ensaios de geopolítica da cidade. Rio de Janeiro: Bertrand Brasil. 2002.

GONZALEZ, Lélia O movimento negro na última década. In: GONZALEZ, Lélia \& HASENBALG, Carlos. Lugar de negro. Rio de Janeiro: Marco Zero, 1982, p. 09-66.

MASSEY, Doreen B. Um sentido global do lugar. In: ARANTES, Antônio (Org). $O$ espaço da diferença. Campinas: Papirus, 2000. P. 176-185.

MESQUITA, Zilá. Do territorio à consciencia territorial. In MESQUITA, Zilá, BRANDÃO, Carlos Rodrigues (Org). Territórios do cotidiano, uma introdução a novos olhares e experiências. Porto Alegre/Santa Cruz do Sul/UNISC, 1995.

PORTO-GONÇALVES, Carlos Walter. A Geograficidade do Social: uma contribuição para o debate metodológico para os estudos de conflitos e movimentos sociais na América Latina. Revista Eletrônica da Associação dos Geógrafos Brasileiros - Seção Três Lagoas - MS, V $1-$ n. $^{\circ} 3$ - ano 3, maio de 2006. Disponível em: <http://www.cptl.ufms.br/revista-geo/carloswalter.pdf>. Acesso em: 20 ago. 2010. 
RAFFESTIN, Claude. Por uma Geografia do Poder. São Paulo: Ática, 1993.

RATTS, Alex. Traços étnicos: Espacialidades e Culturas Negras e Indígenas. Fortaleza: Museu do Ceará: Secult, 2009.

RATTS, Alex. Os lugares da gente negra: raça, gênero e espaço no pensamento de Beatriz Nascimento e Lélia Gonzalez. Comunicação oral apresentada no GT Intersecções entre raça, etnicidade e gênero: africanos(as) e afro-brasileiros(as), conexões diferenciadas e/ou desiguais no XI Congresso Luso-Afro-Brasileiro de Ciências Sociais. Salvador: UFBA, 2011 (mimeo).

RATTS, Alex; RIOS, Flávia. Lélia Gonzalez. São Paulo: Selo Negro, 2010.

RODRIGUES. Ana Paula Costa; RATTS. Alecsandro J .P. Cultura, População Negra e Espaço Público em Goiás: a Congada de Catalão. 2007. Disponível em <http://www.geografia.ufpr.br/neer/NEER-2/Trabalhos_NEER/Ordemalfabetica/Micros oft\%20Word\%20-\%20AnaPaulaCostaRodrigues.ED1IV.pdf > Acesso em: 18 de mai. 2011.

SANTOS, Regina Bega. Movimentos Sociais Urbanos. São Paulo: Editora UNESP, 2008.

SAQUET, Marcos Aurélio. Abordagens e concepções de territórios. $2^{\mathrm{a}}$ ed. - São Paulo: Expressão Popular, 2010.

SILVA, Maria Nilza da. Nem para todos é a cidade: segregação urbana e racial em São Paulo. Brasília: Fundação Cultural Palmares, 2006.

Recebido para publicação em agosto de 2011 Aprovado para publicação em novembro de 2011 